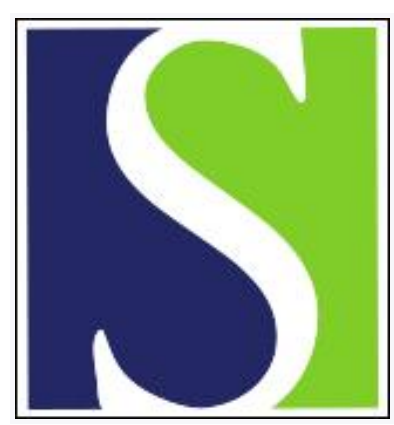

Scand J Work Environ Health 1993;19(3):183-190

https://doi.org/10.5271/sjweh.1483

Issue date: 01 Jun 1993

Toxicokinetics and biological monitoring in experimental exposure of humans to gaseous hexahydrophthalic anhydride. by Jonsson BA, Skerfving $S$

Affiliation: Department of Occupational and Environmental Medicine, University Hospital, Lund, Sweden.

This article in PubMed: www.ncbi.nlm.nih.gov/pubmed/8367696

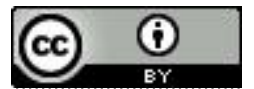




\title{
Toxicokinetics and biological monitoring in experimental exposure of humans to gaseous hexahydrophthalic anhydride
}

\author{
by Bo AG Jönsson, PhD, Staffan Skerfving, $M D^{1}$

\begin{abstract}
JÖNSSON BAG, SKERFVING S. Toxicokinetics and biological monitoring in experimental exposure of humans to gaseous hexahydrophthalic anhydride. Scand J Work Environ Health 1993;19:18390. Six healthy volunteers were exposed to gaseous hexahydrophthalic anhydride (HHPA) concentrations of 10,40 , or $80 \mu \mathrm{g} \cdot \mathrm{m}^{-3}\left(65,260\right.$ or $520 \mathrm{nmol} \cdot \mathrm{m}^{-3}$, respectively) for $8 \mathrm{~h}$. The respiratory uptake of the inhaled HHPA was almost complete. Rapid increases in plasma and urinary levels of hexahydrophthalic acid (HHP acid) were seen. During the first $4 \mathrm{~h}$ after the end of exposure, the half-time of HHP acid in plasma was about $2 \mathrm{~h}$. A corresponding decay was seen in urine. The correlations $(r>0.90)$ between the air concentrations of HHPA and the levels of HHP acid in plasma and urine were close. They were even closer $(r>0.96)$ when the total respiratory uptake of HHPA was used. Urinary $\mathrm{pH}$ adjustment by intake of ammonium chloride or sodium hydrogen carbonate did not significantly alter the excretion of HHP acid. The results show that the analysis of HHP acid in plasma or urine is useful as a biological monitor for exposure to HHPA.
\end{abstract}

Key terms: air, distribution, excretion, determination, half-time, hexahydrophthalic acid, kinetics, plasma, uptake, urine.

Hexahydrophthalic anhydride (HHPA) is an irritant to the eyes and the mucous membranes of the respiratory tract (1) and has been reported to cause occupational asthma and allergic rhinitis (2). Furthermore, HHPA causes allergic sensitization in a large fraction of exposed workers, even at extremely low exposure levels (3). In fact it seems to be one of the most potent airway sensitizers known.

Methods for determining HHPA and the sum of hexahydrophthalic acid (HHP acid) and HHPA (4) in air have been described. However, a method for biologically monitoring exposure to HHPA would also be useful since biological monitoring offers several advantages over air monitoring. It is more convenient and less expensive, and it takes into account variations in pulmonary ventilation and also skin absorption.

HHPA is excreted in the urine as unconjugated HHP acid $(5,6)$. Methods for determining HHP acid in urine have been described (5-7). Results indicate that it may be possible to use the determination of HHP acid in urine as a biological monitor of inhalation exposure to HHPA $(6,7)$. This procedure would demand knowledge of basic toxicokinetic data (eg, the elimination half-time and the effect of urinary $\mathrm{pH}$ on the excretion of HHP acid). However, the toxicokinetics of HHPA are largely unknown.

1 Department of Occupational and Environmental Medicine, University Hospital, Lund, Sweden.

Reprint requests to: Dr B Jönsson, Department of Occupational and Environmental Medicine, University Hospital, S-221 85 Lund, Sweden.
Only few parameters have been evaluated. Furthermore, data are sometimes contradictory. For example, in one report, the half-time has been estimated to be $14 \mathrm{~h}(5)$, while in another the corresponding value was $2-3 \mathrm{~h}(7)$.

The estimation of most toxicokinetic parameters demands access to plasma data. Moreover, the plasma levels have several advantages over those of urine as a method for biological monitoring. With plasma there are no problems with varying dilutions, and the time reflected by the sample is better defined. Moreover, in many cases, plasma is a less complex analytical matrix than urine.

To evaluate further the possibility of biologically monitoring HHPA exposure and to improve existing knowledge of the toxicokinetics of HHPA, we have exposed volunteers to different air levels of HHPA in an exposure chamber. The levels of HHP acid in plasma and urine, the effect of urinary $\mathrm{pH}$ on the excretion of HHP acid, and basic toxicokinetic parameters for HHP acid are reported in this communication.

\section{Subjects and methods}

\section{Subjects}

Six men with an average age of 38 (range 22-55) years participated in the study. Their average weight was 79 (range $70-90$ ) $\mathrm{kg}$. However, after the first provocation at $10 \mu \mathrm{g} \cdot \mathrm{m}^{-3}\left(65 \mathrm{nmol} \cdot \mathrm{m}^{-3}\right)$, one person (age 51 years, weight $83 \mathrm{~kg}$ ) chose, for personal reasons, not to participate further in the study. One of the participants was a smoker. All the participants were given a general medical examination before the 
experiment and were judged healthy. Plasma concentrations of albumin, alpha -antitrypsin, orosomucoid, haptoglobin, C-reactive protein, and the immunoglobulins G, A, M and E of the participants were within the reference limits. Furthermore, the methacholine test and spirometry were "normal." The subjects had negative skin prick tests with both a standard panel of 14 common allergens and with a conjugate between human serum albumin and HHPA (8). The experiments were approved by the Ethics Committee of the Lund University. All of the participants signed an informed consent.

\section{Experimental design}

Controlled atmospheres of HHPA were generated with a permeation technique $(9,10)$. Permeation tubes with membranes of silicon rubber were filled with HHPA from Merck (Darmstadt, Germany) and placed in a permeation chamber. Dry air was blown through the permeation chamber and the obtained HHPA atmosphere was mixed with air from a climate device. The combined air was blown into an $8-\mathrm{m}^{3}$ exposure chamber. Different concentrations were generated by varying the temperature of the water bath. The air concentrations of HHPA were continuously monitored by XAD-2 tubes (4) and a fourier-transform infrared spectrometer (Bomem MB100, Bomem, Quebec, Canada).

The subjects were exposed to three different concentrations of HHPA on three different occasions. The time between the different exposures was never less than one week. The exposures lasted $8 \mathrm{~h}$ and were interrupted for $5 \mathrm{~min}$ at 2 and $6.5 \mathrm{~h}$ after the beginning of the exposure for urine collection, and, if required, blood sampling, and for $30 \mathrm{~min}$ at $4 \mathrm{~h}$ for lunch. The intended concentrations were 10,40 , and $80 \mu \mathrm{g} \cdot \mathrm{m}^{-3}\left(65,260\right.$, and $\left.520 \mathrm{nmol} \cdot \mathrm{m}^{-3}\right)$, and the obtained means of the time-weighted average (TWA) concentrations were 10,37 , and $81 \mu \mathrm{g} \cdot \mathrm{m}^{-3}(65,240$, and $\left.525 \mathrm{nmol} \cdot \mathrm{m}^{-3}\right)$, respectively. The coefficient of variation of the TWA air concentrations was $15 \%$ for the six 8 -h exposures at $10 \mu \mathrm{g} \cdot \mathrm{m}^{-3}, 5 \%$ for the five exposures at $37 \mu \mathrm{g} \cdot \mathrm{m}^{-3}$, and $6 \%$ for the nine exposures at $81 \mu \mathrm{g} \cdot \mathrm{m}^{-3}$. The variation of the concentration of HHPA in air $\left(10 \mu \mathrm{g} \cdot \mathrm{m}^{-3}\right)$ during $8 \mathrm{~h}$ of exposure was $3 \%(\mathrm{~N}=8)$, as determined by $1-\mathrm{h}$ XAD-2 samplings. The subjects were at physical rest during the exposure and only desk work was performed.

\section{Individual ventilation}

At $1,2,4.5$, and $6.5 \mathrm{~h}$ after the beginning of the exposure, the subjects breathed through a valve into a polyethylene-aluminum Douglas bag for $10 \mathrm{~min}$. The volumes of the exhaled air in the bags were measured by suction of the air at $3.01 \cdot \mathrm{min}^{-1}$ with a GilAir pump (Gilian Instruments, Wayne, New Jersey, United States). The individual ventilation during the exposure was estimated from the mean of these measurements.

\section{Air sampling}

The sampling of HHPA in air was performed by duplicate stationary sampling on Amberlite XAD-2 tubes (cat no 226-30, SKC, Eighty Four, Pennsylvania, United States), as previously described (4). The sampling was performed close to the breathing zone of the subjects. The sampling time was about $1 \mathrm{~h}$, and the sampling rate was $1.0 \mathrm{l} \cdot \mathrm{min}^{-1}$. The tubes were stored at $-20^{\circ} \mathrm{C}$ until the analysis.

The sampling of HHPA and HHP acid in air expired into the Douglas bags was performed by suction of the air (see the section "Individual Ventilation") through a bubbler containing $0.1 \mathrm{M}$ sodium hydroxide $(\mathrm{NaOH})$. After being emptied, the bags and valves were washed with $100 \mathrm{ml}$ of $0.1 \mathrm{M}$ $\mathrm{NaOH}$. The bubbler and washing solutions were mixed, and the volumes measured. Negligible amounts of HHP acid were found in the valves and the bags after a second washing.

\section{Collection of urine and blood}

Urine was collected into polyethylene bottles immediately before the start of the exposure and then after $2,4,6.5,8.5,10.5,12.5,14.5,24,26$, and $28 \mathrm{~h}$. In addition, for exposures at $80 \mu \mathrm{g} \cdot \mathrm{m}^{-3}$, urine was also collected after 9.5 and $11.5 \mathrm{~h}$. The $\mathrm{pH}$ of the urine was determined by the strip test (Neutralit, $\mathrm{pH}$ $5-10$, Merck). The concentration of creatinine in urine was determined by Jaffe's method (11) as modified by Masson (personal communication, Masson $P$, Department of Clinical Chemistry, University Hospital, Lund, Sweden). The urine was stored in a freezer at $-20^{\circ} \mathrm{C}$ until the analysis.

Blood samples were obtained from an antecubital vein and collected in tubes containing ethylenediaminetetraacetic acid (EDTA). The sampling was performed before the beginning of exposure, at $4 \mathrm{~h}$, and immediately after the end of exposure. After the sampling, the blood was allowed to cool and was then centrifuged ( $1500 \mathrm{~g}, 10 \mathrm{~min})$. The plasma was transferred to Nunc CryoTubes (Roskilde, Denmark) and stored in a freezer at $-20^{\circ} \mathrm{C}$ until the analysis.

\section{Studies of the effect of $p H$ in urine}

Two of the volunteers (age 29 and 55 years, weight 90 and $87 \mathrm{~kg}$ ) participated in an additional study on the effect of $\mathrm{pH}$ on the excretion of HHP acid in urine. The air concentration was $80 \mu \mathrm{g} \cdot \mathrm{m}^{-3}$. There was one exposure with unadjusted $\mathrm{pH}$ in urine and, for each volunteer, two additional exposures in which the $\mathrm{pH}$ of the urine was adjusted. To make the urine acidic, we gave the subjects repeated doses of ammonium chloride ( $4 \mathrm{~g} 12 \mathrm{~h}$ before, and $2 \mathrm{~g} 2$ and $1 \mathrm{~h}$ before and at the start of the exposure, and then $2 \mathrm{~g}$ after 2, 6, 10, 14, and $23 \mathrm{~h}$ ). For alkaline urine, the subjects were given repeated doses of sodium hydrogen carbonate $(3 \mathrm{~g} 2 \mathrm{~h}$ before and $2 \mathrm{~g} 1 \mathrm{~h}$ before and at the start of the exposure and then $2 \mathrm{~g}$ after 4 , 8,14 , and $23 \mathrm{~h}$ ). The urine was sampled immediately 
before the beginning of the exposure and then after $2,4,6.5,8.5,9.5,10.5,11.5,12.5,14.5,24,26$, and $28 \mathrm{~h}$. Blood was sampled before the beginning of the exposure and then after $2,4,6.5,8.5,9.5,10.5,11.5$, $12.5,14.5,24$, and $28 \mathrm{~h}$.

\section{Analyses}

For the analysis of the air samples, the XAD-2 tubes were eluted in toluene, and an aliquot of the eluate was injected into a gas chromatograph (GC) equipped with a flame ionization detector (4).

The analysis of HHP acid in urine was performed as reported earlier (6). A deuterium-labeled internal standard was added to the urine. Acidic hydrolysis was performed, and the HHP acid in the urine was then extracted by use of octadecyl $\left(\mathrm{C}_{18}\right)$ Bond Elut and SAX Bond Elut columns (Analytichem International, Harbor, California, United States). The eluate from the extraction was evaporated to dryness and esterified with methanol and boron trifluoride. Saturated sodium bicarbonate solution was then added, and the mixtures were extracted with toluene. An aliquot of the toluene solution was injected into a gas chromatograph connected with a mass spectrometer (MS).

For the analysis of HHP acid in plasma, $100 \mu \mathrm{l}$ of $100 \mathrm{ng} \cdot \mathrm{ml}^{-1}$ deuterium-labeled HHP acid (internal standard) in $0.01 \mathrm{M} \mathrm{NaOH}$ and $4 \mathrm{ml}$ of water were added to $2 \mathrm{ml}$ of plasma. Standard solutions were prepared through the addition of known amounts of HHP acid in $0.01 \mathrm{M} \mathrm{NaOH}$ solutions to blank plasma. The samples were then acidified by $200 \mu 1$ of $6 \mathrm{M}$ hydrogen chloride $(\mathrm{HCl})$. The precipitates were removed by centrifugation at $1500 \mathrm{~g}$ for $10 \mathrm{~min} . \mathrm{C}_{18}$ Bond Elut columns $(500 \mathrm{mg}$, Analytichem International) were conditioned by $5 \mathrm{ml}$ of methanol and then with $10 \mathrm{ml}$ of $0.1 \mathrm{M} \mathrm{HCl}$. The centrifuged samples were then sucked through the columns, which resulted in the trapping of the HHP acid. Thereafter, $10 \mathrm{ml}$ of $0.1 \mathrm{M} \mathrm{HCl}$ :methanol (95:5) was used for washing. After the columns were dried by suction of air for $5 \mathrm{~min}$, the HHP acid was eluted with $3 \mathrm{ml}$ of $0.1 \mathrm{M}$ Tris [tris(hydroxymethyl)aminomethane] buffer ( $\mathrm{pH} 8.8$ ). SAX Bond Elut columns $(500 \mathrm{mg}$, Analytichem International) were conditioned with $5 \mathrm{ml}$ of methanol, $10 \mathrm{ml}$ of $1.0 \mathrm{M}$ sodium acetate, and $10 \mathrm{ml}$ of water. The HHP acid eluates were then applied to the SAX columns. Washing was performed with $5 \mathrm{ml}$ of $0.01 \mathrm{M}$ Tris buffer(pH 8.2):methanol (70:30). The columns were dried by centrifugation at $1500 \mathrm{~g}$ for $10 \mathrm{~min}$ and then by air suction for 5 min. Elution of the HHP acid was performed by $3 \mathrm{ml}$ of formic acid:methanol (50:50). The samples were evaporated to dryness with an AS290 SpeedVac system (Savant, Farmingdale, New York, United States). To the dry residues containing the HHP acid, $1 \mathrm{ml}$ of methanol and $2 \mathrm{ml}$ of $14 \%$ boron trifluoride in methanol were added. Esterification was performed overnight at $70^{\circ} \mathrm{C}$. After the samples were cooled to room temperature, $4 \mathrm{ml}$ of saturated sodium bicarbonate solution and $1 \mathrm{ml}$ of toluene were added. The solution was shaken for 15 $\mathrm{min}$ and then centrifuged at $1500 \mathrm{~g}$ for $3 \mathrm{~min}$. A $2-\mu 1$ aliquot of the toluene phase was injected with a Carlo Erba A200S autosampler into a Carlo Erba 8065 (Milan, Italy) gas chromatograph, connected with a Trio 1000 mass spectrometer from VG Mass Lab (Fisons, Manchester, United Kingdom). The temperature in the split/splitless injector was $230^{\circ} \mathrm{C}$. The column was a fused silica capillary column $(30 \mathrm{~m} \times 0.25 \mathrm{~mm}$ inner diameter) coated with a DB-5 stationary phase with a film thickness of $0.25 \mu \mathrm{m}$ (J\& W Scientific, Folsom, California, United States). The column temperature programming was $110^{\circ} \mathrm{C}$ for $2 \mathrm{~min}$ and then $15^{\circ} \mathrm{C}$ per minute until $290^{\circ} \mathrm{C}$, when cooling was immediately started. The temperature in the GC-MS interface and the ionsource was $200^{\circ} \mathrm{C}$. The mass spectrometer was in the electron impact (EI) mode $(70 \mathrm{eV})$ and the ion fragments at $\mathrm{m} / \mathrm{z}=140$ (HHP acid dimethyl ester) and $\mathrm{m} / \mathrm{z}=145$ (internal standard) were used. The precision of the method was $3 \%(\mathrm{~N}=7)$ at a concentration of $17 \mathrm{nmol} \cdot 1^{-1}$ plasma. The limit of detection, according to the Miller \& Miller definition (12), was $2 \mathrm{nmol} \cdot \mathrm{1}^{-1}$ plasma.

For the analysis of HHPA and HHP acid in expired air, $100 \mu \mathrm{l}$ of $500 \mathrm{ng} \cdot \mathrm{ml}^{-1}$ hexadeuterium-labeled HHP acid (internal standard) in $0.01 \mathrm{M} \mathrm{NaOH}$ was added to $10 \mathrm{ml}$ of the mixed bubbler and washing solution. (See the preceding text.) The solutions were acidified with $0.5 \mathrm{ml}$ of $5 \mathrm{M} \mathrm{HCl}$. $\mathrm{C}_{18}$ Bond Elut columns $(500 \mathrm{mg}$ ) were conditioned by $5 \mathrm{ml}$ of methanol and $10 \mathrm{ml}$ of $0.1 \mathrm{M} \mathrm{HCl}$. Thereafter, the acidified samples were applied to the columns followed by $5 \mathrm{ml} 0.1 \mathrm{M} \mathrm{HCl}$. The columns were dried by centrifugation at $1500 \mathrm{~g}$ for $10 \mathrm{~min}$ and thereafter by suction of air for $5 \mathrm{~min}$. Elution was performed by $2 \mathrm{ml}$ of methanol in glass test tubes with Teflon ${ }^{\circledast}$ screw caps, and $2 \mathrm{ml}$ of $14 \%$ boron trifluoride in methanol was then added. Esterification was performed overnight at $70^{\circ} \mathrm{C}$. When the tubes had cooled, $4 \mathrm{ml}$ of saturated sodium bicarbonate was added, and the mixtures were extracted with $2 \mathrm{ml}$ of toluene. After centrifugation, $2 \mu \mathrm{l}$ of the toluene solution was injected with a splitless technique at $200^{\circ} \mathrm{C}$ with a Carlo Erba A200S autosampler into a Carlo Erba 8065 gas chromatograph, connected with a Trio 1000 mass spectrometer from the VG Mass Laboratory. The column was a J\&W capillary column (DB$5,30 \mathrm{~m} \times 0.25 \mathrm{~mm}$ inner diameter, film thickness $0.25 \mu \mathrm{m})$. The column temperature program on the GC-MS was as follows: (i) $110^{\circ} \mathrm{C}$ for $2 \mathrm{~min}$, (ii) $230^{\circ} \mathrm{C}\left(20^{\circ} \mathrm{C} / \mathrm{min}\right)$. The temperature of the interface and ion source was $200^{\circ} \mathrm{C}$, and the mass spectrometer was in the EI mode at $70 \mathrm{eV}$. The ion fragments at $\mathrm{m} / \mathrm{z}=140$ (HHP acid dimethyl ester) and $\mathrm{m} / \mathrm{z}=145$ (internal standard) were used. The limit of detection corresponded to about $10 \mathrm{ng}$ of exhaled HHPA. 


\section{Toxicokinetic calculations}

The respiratory uptake of HHPA was calculated as the concentration in inhaled air multiplied by the individual ventilation. No account was taken of the small amounts of HHPA in the exhaled air. The elimination half-time of HHP acid was calculated by linear regression from diagrams of the natural logarithm of the excretion of HHP acid in urine, or concentrations of HHP acid in plasma, versus the postexposure time, where the slope was the negative value of the elimination rate constant. In plots of urine HHP acid excretion versus time, the middle of the time interval was used. The total area under the plasma concentration-time curve (AUC) for HHP acid was calculated by the trapezoidal rule (13). Total clearance from plasma was calculated for HHP acid as the dose, divided by the AUC (13), where the dose was substituted by the total respiratory uptake during the exposure. The apparent volume of distribution of HHP acid was calculated as the total clearance from plasma divided by the elimination rate constant (13). The renal clearance of HHP acid was calculated from the slope in a diagram in which the areas under the plasma concentration-time curve within the sampling intervals were plotted versus the amount excreted in the urine during the same interval (13).

\section{Results}

The concentration of HHPA in exhaled air from five subjects, exposed at $80 \mu \mathrm{g} \cdot \mathrm{m}^{-3}$, was found to be 3 (range $1-4$ ) \% of the concentration in inhaled air.
The concentration of HHP acid in plasma rose rapidly during the same exposure, and the decay was equally rapid during the postexposure period (figure 1). Steady state was not reached during the exposure. Two subjects had plasma concentrations below the limit of detection $15.5 \mathrm{~h}$ after the end of the exposure. The half-times of HHP acid in plasma, as calculated from the concentrations during the first $4 \mathrm{~h}$ after the end of the exposure were 1.7 and $1.8 \mathrm{~h}$ for two subjects.

The excretion rate of HHP acid in urine rose rapidly during the exposure, and the levels also decayed steeply after the end of the exposure (figure 2). At the end of the exposure, the excretion was close to a steady state. At $15.5 \mathrm{~h}$ after the end of the exposure, the levels of one subject exposed to $10 \mu \mathrm{g}$. $\mathrm{m}^{-3}$, three subjects exposed to $40 \mu \mathrm{g} \cdot \mathrm{m}^{-3}$, and three subjects exposed to $80 \mu \mathrm{g} \cdot \mathrm{m}^{-3}$ were still above the limit of detection of HHP acid in urine. All of the subjects had urine concentrations below the limit of detection after $19.5 \mathrm{~h}$. The half-time of HHP acid was estimated from the excretion rates of HHP acid for five subjects exposed to $80 \mu \mathrm{g} \cdot \mathrm{m}^{-3}$. The half-time was 2.1 (range 1.6-2.8) $\mathrm{h}$ when the data on urine collected during the first $4.5 \mathrm{~h}$ after the end of exposure was used. For urine collected during $20 \mathrm{~h}$ after the end of exposure, the half-time was 2.8 (range 2.6-3.3) h.

The total amount of HHP acid excreted during exposure and during the postexposure periods, as a fraction of the total respiratory uptake, was 130 (range $95-156) \%$ at the exposure level of $10 \mu \mathrm{g}$. $\mathrm{m}^{-3}, 130$ (range $\left.110-158\right) \%$ at $40 \mu \mathrm{g} \cdot \mathrm{m}^{-3}$, and 106 (range $79-133$ ) $\%$ at $80 \mu \mathrm{g} \cdot \mathrm{m}^{-3}$. There was a cor-

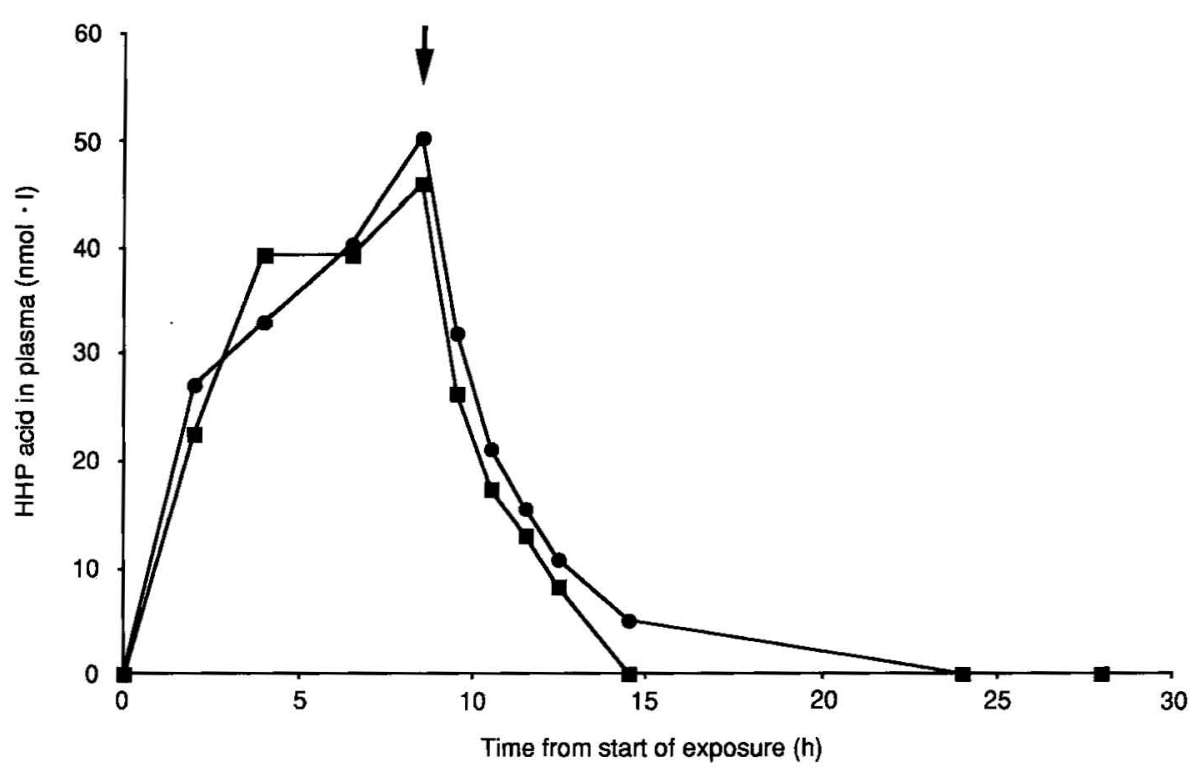

Figure 1. Hexahydrophthalic acid (HHP acid) in plasma in two subjects before, during, and after exposure to hexahydrophthalic anhydride at about $80 \mu \mathrm{g} \cdot \mathrm{m}^{-3}\left(520 \mathrm{nmol} \cdot \mathrm{m}^{-3}\right)$ for $8 \mathrm{~h}$ (end of exposure at arrow). 


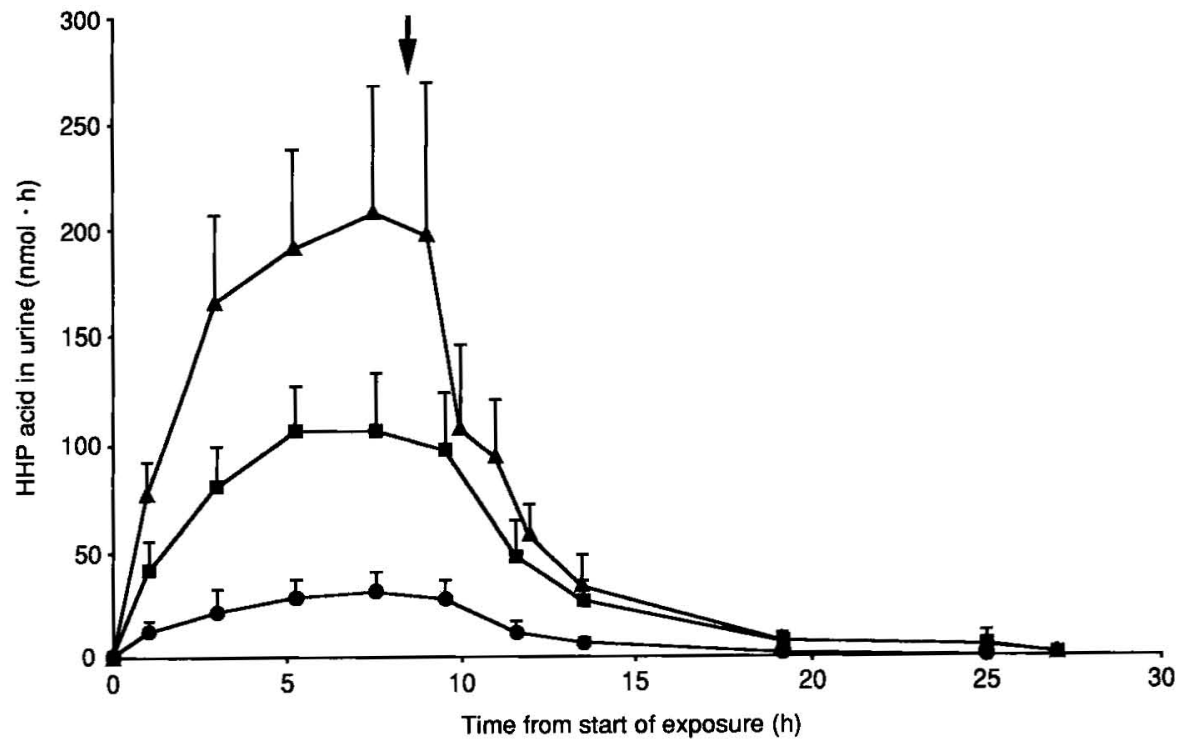

Figure 2. Hexahydrophthalic acid (HHP acid) excretion in urine before, during, and after exposure to hexahydrophthalic anhydride (HHPA) for $8 \mathrm{~h}$. The upper ranges of the standard deviations are included. (Closed circles $=$ mean of six subjects during an average exposure of $10 \mu \mathrm{g} \cdot \mathrm{m}^{-3}\left(65 \mathrm{nmol} \cdot \mathrm{m}^{-3}\right)$, squares $=$ mean of five subjects at $37 \mu \mathrm{g} \cdot \mathrm{m}^{-3}(240 \mathrm{nmol}$. $\left.\mathrm{m}^{-3}\right)$, and triangles $=$ mean of five subjects at $81 \mu \mathrm{g} \cdot \mathrm{m}^{-3}\left(525 \mathrm{nmol} \cdot \mathrm{m}^{-3}\right)$, arrow $=$ end of exposure)

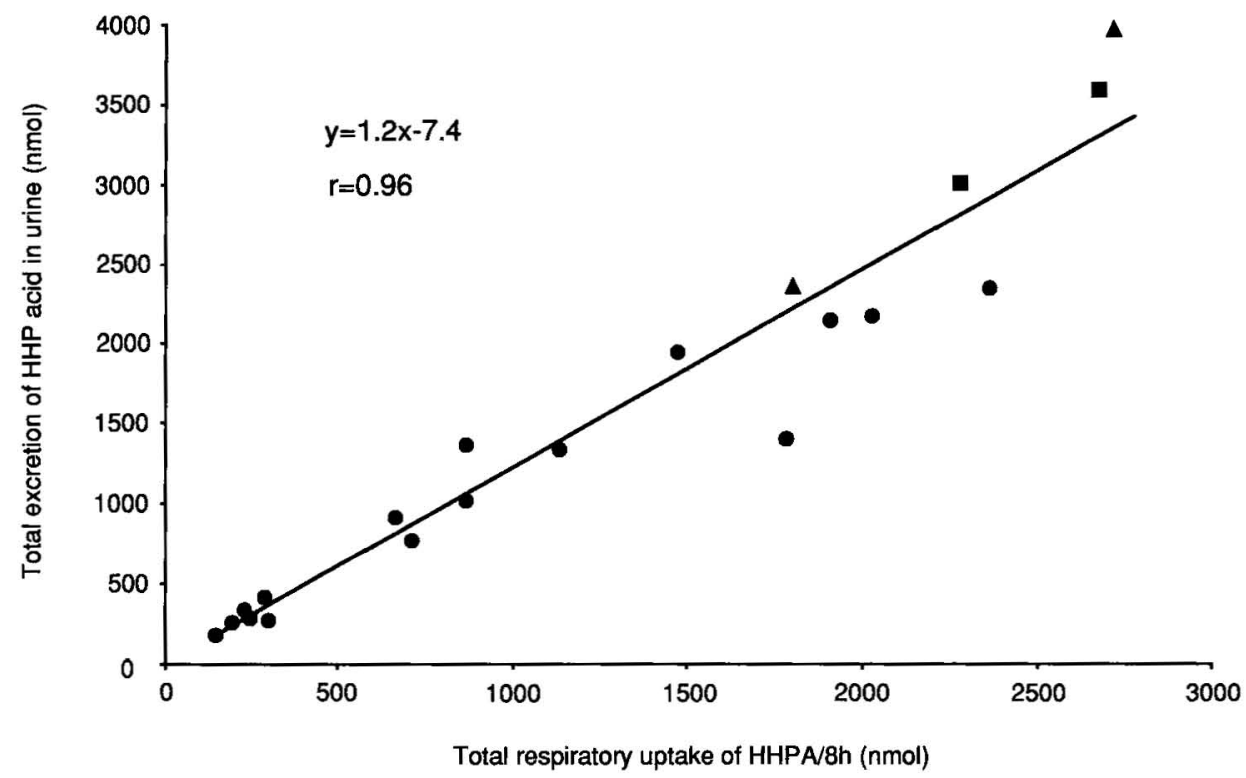

Figure 3. Total excreted amount of hexahydrophthalic acid (HHP acid) in urine during and after exposure versus the calculated total respiratory uptake of hexahydrophthalic anhydride (HHPA) during exposure. (Closed circles $=$ samples from exposures in which the urinary $\mathrm{pH}$ was not adjusted, squares = samples from two exposures in which the $\mathrm{pH}$ was adjusted to about 5.2, and triangles = samples from two exposures in which the $\mathrm{pH}$ was adjusted to about 7.4).

relation $(r=0.96)$ between the calculated total respiratory uptake and the total amount of HHP acid excreted in urine during exposure and during the postexposure periods (figure 3 ).

There was a close correlation $(r=0.94)$ between the TWA concentration of HHPA in air and the level of HHP acid in plasma collected immediately after the end of exposure (figure 4a). When the total respiratory uptake during exposure was used instead of the concentration in air, the correlation coefficient was even higher $(r=0.98)$ (figure $4 b)$.

There were also close correlations between the TWA concentration of HHPA in air $(r=0.92)$ and the total respiratory uptake during exposure $(r=0.97)$ 

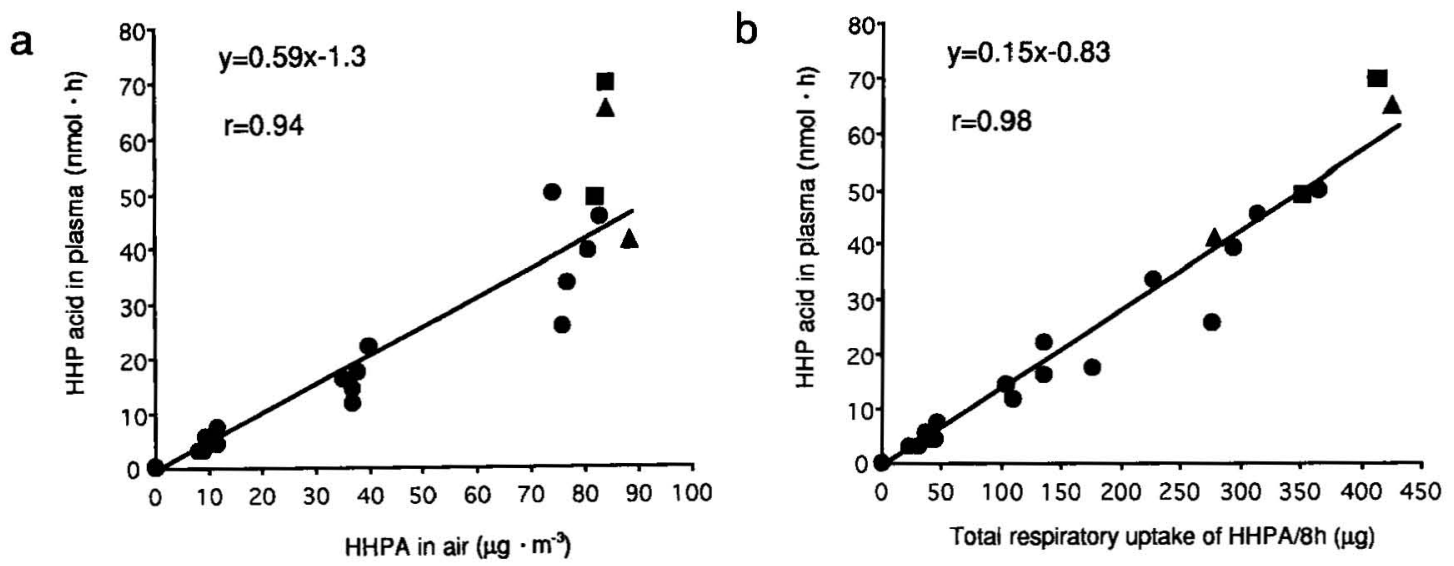

Figure 4. Hexahydrophthalic acid (HHP acid) in plasma after the end of exposure versus the time-weighted average concentration of hexahydrophthalic anhydride (HHPA) in air (a) and HHP acid in plasma after the end of exposure versus the calculated total respiratory uptake of HHPA during exposure (b). Concentrations from six subjects sampled before the beginning of exposure have been plotted at zero exposure. (Closed circles = samples from exposures in which the urinary $\mathrm{pH}$ was not adjusted, squares $=$ samples from two exposures in which the $\mathrm{pH}$ was adjusted to about 5.2 , and triangles $=$ samples from two exposures in which the $\mathrm{pH}$ was adjusted to about 7.4 )

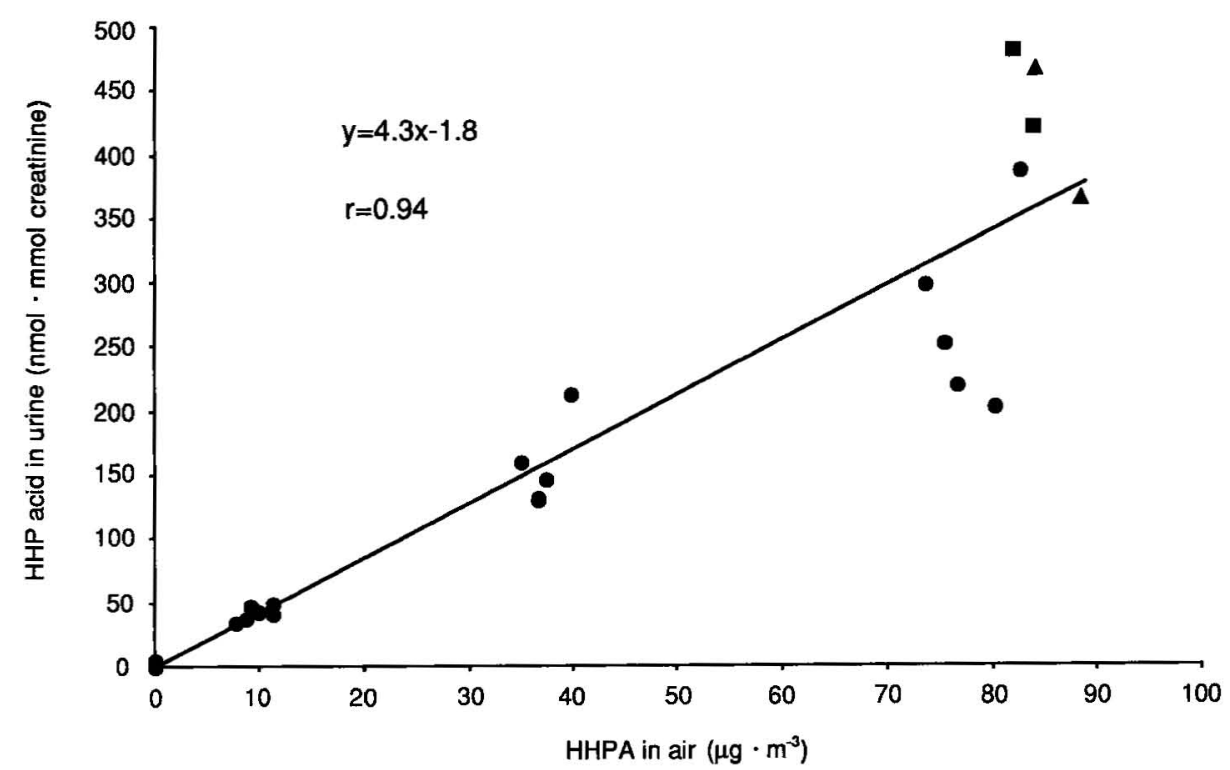

Figure 5. Hexahydrophthalic acid (HHP acid) in urine during the last $2 \mathrm{~h}$ of an 8-h exposure versus the time-weighted average concentration of hexahydrophthalic anhydride (HHPA) in air. Levels from six subjects sampled before the beginning of exposure have been plotted at zero exposure. (Closed circles = samples from exposures in which the urinary pH was not adjusted, squares = samples from two exposures in which the $\mathrm{pH}$ was adjusted to about 5.2, and triangles $=$ samples from two exposures in which the $\mathrm{pH}$ was adjusted to about 7.4)

on the one hand and the excretion rate of HHP acid in urine during the last $2 \mathrm{~h}$ of exposure on the other. When the creatinine-adjusted HHP acid excretion was used, the correlation with the TWA concentration of HHPA in air remained $(r=0.94)$ (figure 5).

The toxicokinetic parameters of HHP acid were calculated for the two subjects who participated in the frequent plasma sampling (table 1, values from experiments without adjustment of urinary $\mathrm{pH}$ ). Their half-times in plasma were 1.7 and $1.8 \mathrm{~h}$. Both renal and total clearance was about $6 \mathrm{l} \cdot \mathrm{h}^{-1}$, the former being slightly higher than the latter. The volumes of distribution were about 14 and $15 \mathrm{l}$, respectively.

In the same two subjects, the $\mathrm{pH}$ was adjusted through the ingestion of ammonium chloride or sodium hydrogen carbonate (table 1). This procedure did not significantly affect any of the toxicokinetic parameters. However, it seems that the renal clearance rises somewhat as the $\mathrm{pH}$ increases. 
Table 1. Estimates of toxicokinetic parameters for hexahydrophthalic acid in two men from 8-h exposures at a hexahydrophthalic anhydride concentration of $80 \mu \mathrm{g} \cdot \mathrm{m}^{-3}\left(520 \mathrm{nmol} \cdot \mathrm{m}^{-3}\right)$.

\begin{tabular}{|c|c|c|c|c|c|c|c|c|c|}
\hline Subject & $\mathrm{pH}$ & $\begin{array}{c}\text { Coefficient } \\
\text { of variation } \\
\text { for the } \mathrm{pH} \\
(\%)\end{array}$ & $\begin{array}{c}\text { Total } \\
\text { respiratory } \\
\text { uptake } \\
\text { (nmol) }\end{array}$ & $\begin{array}{c}\text { Elimination } \\
\text { rate } \\
\text { constanta } \\
\left(h^{-1}\right)\end{array}$ & $\begin{array}{l}\text { Half-time } \\
\text { in plasma } \\
\text { (h) }\end{array}$ & $\underset{\left(\mathrm{nmol} \cdot \mathrm{h} \cdot \mathrm{I}^{-1}\right)}{\text { AUC }}$ & $\begin{array}{c}\text { Clearance } \\
\text { from } \\
\text { plasma } \\
(\mid \cdot h-1)\end{array}$ & $\begin{array}{c}\text { Renal } \\
\text { clearance } \\
\left(1 \cdot h^{-1}\right)\end{array}$ & $\begin{array}{l}\text { Volume of } \\
\text { distribution } \\
\text { (I) }\end{array}$ \\
\hline $\begin{array}{l}1 \\
1 \\
1 \\
2 \\
2 \\
2\end{array}$ & $\begin{array}{l}6.4 \\
5.2^{c} \\
7.2^{d} \\
6.2^{2} \\
5.1^{c} \\
7.5^{d}\end{array}$ & $\begin{array}{r}8 \\
3 \\
11 \\
9 \\
3 \\
7\end{array}$ & $\begin{array}{l}2360 \\
2570 \\
2600 \\
2030 \\
2280 \\
1810\end{array}$ & $\begin{array}{l}0.38 \\
0.26 \\
0.31 \\
0.41 \\
0.32 \\
0.41\end{array}$ & $\begin{array}{l}1.8 \\
2.6 \\
2.2 \\
1.7 \\
2.1 \\
1.7\end{array}$ & $\begin{array}{l}410 \\
602 \\
590 \\
361 \\
480 \\
330\end{array}$ & $\begin{array}{l}5.7 \\
4.3 \\
4.4 \\
5.6 \\
4.7 \\
5.5\end{array}$ & $\begin{array}{l}6.2 \\
5.9 \\
6.6 \\
5.9 \\
5.7 \\
6.6\end{array}$ & $\begin{array}{l}15.2 \\
16.3 \\
14.3 \\
13.7 \\
14.6 \\
13.3\end{array}$ \\
\hline
\end{tabular}

a The elimination rate constants and the half-times were calculated from plasma concentrations sampled during $4 \mathrm{~h}$ immediately after the end of exposure.

Area under the blood concentration-time curve (13)

c The $\mathrm{pH}$ in urine was adjusted by the ingestion of ammonium chloride.

d The $\mathrm{pH}$ in urine was adjusted by the ingestion of sodium hydrogen carbonate.

\section{Discussion}

The present data show that HHPA is almost completely absorbed from the respiratory tract and is rapidly distributed, probably as HHP acid, in a relatively small volume. Furthermore, HHP acid is excreted through the kidneys by a mechanism unaffected by urinary $\mathrm{pH}$. The elimination half-time is about $2 \mathrm{~h}$. Moreover, levels of HHP acid in plasma and urine can be used for the biological monitoring of exposure to HHPA.

The concentration of HHPA in expired air was low, as compared with that in inhaled air, and was, for this reason, not included in the calculations of the respiratory uptake. The low concentration of HHPA in the expired air, together with the rapid increase and immediate decay of the plasma concentration of HHP acid and the rapid and high excretion of HHP acid in urine, indicated a fast and complete absorption of either HHPA as such or of HHP acid after hydrolysis on the mucous membranes in the respiratory tract.

It is possible that the absorbed HHPA was proteinbound in plasma, as it is known that organic acid anhydrides bind to proteins and peptides $(14,15)$. However, strong acid hydrolysis gave recoveries similar to the ones obtained by the weaker acid conditions employed in the present analytical procedure. Thus protein binding, if any, should not decrease the recovery. In urine, there was no conjugated HHP acid $(5,6)$.

Our methods were used to determine the levels of HHP acid in plasma and urine, although it cannot be excluded that they also monitor HHPA. However, HHPA in solution reacts readily with water. At $20^{\circ} \mathrm{C}$ and $\mathrm{pH} \mathrm{5.2,} \mathrm{the} \mathrm{half-time} \mathrm{of} \mathrm{HHPA} \mathrm{in} \mathrm{water} \mathrm{is} \mathrm{only}$ 1 min (16). Thus it is highly probable, although not completely certain, that HHPA does not persist in the body, but is rapidly hydrolyzed to HHP acid. This conclusion is contrary to what has been reported for methylhexahydrophthalic anhydride (MHHPA), an acid anhydride closely related to HHPA chemically (17). Thus, surprisingly, high levels of MHHPA have been determined as such in human blood after occupational exposure to that compound.
The volume of distribution of 13 to 161 possibly indicates that HHP acid was distributed mainly in the extracellular water.

The excretion of HHP acid in urine seemed to be close to steady state at the end of exposure, while this was not the case in plasma. We think, however, that most of this difference is an artifact. Thus the plasma values showed the concentration at the time the sample was taken, whereas the urine sample reflected the amount excreted during a longer period before the sample collection. The plasma samples taken after $6.5 \mathrm{~h}$ of exposure were relatively low in HHP acid because of the recent break in the exposure for lunch. This effect was less pronounced in urine.

During the first period after the end of exposure, the urinary elimination curve of HHP acid was in accordance with a half-time of about $2 \mathrm{~h}$. However, later on, the half-time seemed to be longer. This occurrence may indicate elimination from more than one compartment. However, the slow compartment could be an artifact, since the concentrations of HHP acid in the last samples were few and uncertain in many cases because they were close to the detection limit. Thus we made no attempt to calculate a halftime for a slow compartment. Certainly, the amount of HHP acid excreted during any slow phase is small compared with the amount excreted during the initial phase.

The rapid elimination of HHP acid will result in no, or at most, very minor accumulation of HHP acid in the body during a week of occupational exposure. During weekends, complete elimination can be assumed. This assumption is supported by data previously reported for workers exposed in industry (7).

The high correlations between the calculated total respiratory uptake on one hand and the concentrations in plasma and excreted amounts of HHP acid in urine on the other showed precise performance of the Douglas bag procedure. However, when the calculated total respiratory uptake was compared with the total excreted amount of HHP acid, the latter was higher. A probable explanation for this phenomenon is that recovery at the determination of HHPA in air 
was less than complete, and this difference was not adjusted for. Parallel sampling by XAD- 2 tubes and bubblers in the exposure chamber gave similar results (unpublished). Since XAD-2 tubes only sample HHPA, while bubblers retain both HHPA and HHP acid, there were no significant amounts of HHP acid in the chamber air. However, minor absorption through the skin is possible. The presumed too low an estimate of the total respiratory uptake led to an underestimate of the total clearance. Thus the elimination was probably only through the kidney.

There were very close associations between the total respiratory uptake and the concentration of HHPA in plasma and the excreted amounts of HHP acid in urine. This result shows the value of biological monitoring. For such monitoring, measurements of HHP acid in plasma and urine are useful. In practice, creatinine-adjusted urinary levels may be preferable to the determination of excretion rate.

Due to the fast elimination of HHP acid, its monitoring in plasma or urine gives information on exposure on a particular day only. In fact, the half-time is so short that high exposure at the beginning of the workshift is underestimated if urine or plasma is sampled only after work. If such an exposure pattern is expected, sampling should be made earlier during the workshift.

The renal clearance of HHP acid decreased slightly as the acidity of the urine increased. In addition the half-time displayed a tendency in the same direction. However, the $\mathrm{pH}$ of the urine did not seem to affect significantly either the concentration of HHP acid in postexposure plasma or the excretion of HHP acid in postexposure urine. Thus the small effect on the excretion of HHP acid by urinary $\mathrm{pH}$ should cause no problem for the use of our methods in biological monitoring.

There are no permissible exposure limits for HHPA. Thus a biological exposure limit cannot be proposed. However, in an earlier report, we found industrial levels of about $50 \mu \mathrm{g} \cdot \mathrm{m}^{-3}$ (in a plant with a worker population with frequent airway complaints). In the present study this air level of HHPA corresponded to HHP acid levels of $30 \mathrm{nmol} \cdot \mathrm{l}^{-1}$ in plasma and $220 \mathrm{nmol} \cdot \mathrm{mmol}^{-1}$ of creatinine in urine.

\section{Acknowledgments}

We would like to thank Ms B Björk and C Lindh, $\mathrm{BSc}$, for their assistance with the experiment and $\mathrm{H}$ Welinder, $\mathrm{PhD}$, and $\mathrm{G}$ Skarping, $\mathrm{PhD}$, for their valuable help and discussion.

We also acknowledge the Swedish Work Environment Fund and the Medical Faculty at Lund University for their financial support.

\section{References}

1. Venables KM. Low molecular weight chemicals, hypersensitivity, and direct toxicity: the acid anhydrides. Br J Ind Med 1989;46:222-32.

2. Moller DR, Gallagher JS, Bernstein DI, Wilcox TG, Burroughs HE, Bernstein IL. Detection of IgE-mediated respiratory sensitization in workers exposed to hexahydrophthalic anhydride. J Allergy Clin Immunol 1985;75:663-72.

3. Welinder H. Occupational airways hypersensitivity to some small organic molecules: exposure, response, and pathomechanism [dissertation]. Lund (Sweden): Lund University, 1991.

4. Jönsson B, Welinder H, Skarping G. Determination of hexahydrophthalic anhydride in air using gas chromatography. J Chromatogr 1991;558:247-56.

5. Pfäffli P, Savolainen H, Keskinen H. Determination of carboxylic acids in biological samples as their trichloroethyl esters by gas chromatography. Chromatographia $1989 ; 27: 483-8$.

6. Jönsson B, Skarping G. Method for the biological monitoring of hexahydrophthalic anhydride by the determination of hexahydrophthalic acid in urine using gas chromatography and selected-ion monitoring. J Chromatogr 1991;572:117-31.

7. Jönsson B, Welinder H, Skarping G. Hexahydrophthalic acid in urine as an index of exposure to hexahydrophthalic anhydride. Int Arch Occup Environ Health 1991;63:77-9.

8. Welinder $\mathrm{H}$, Nielsen J. Immunologic tests of specific antibodies to organic acid anhydrides. Allergy 1991; 46:601-9.

9. Dharmarajan V, Rando RJ. A new method for the generation of standard atmospheres of organo isocyanates. Am Ind Hyg Assoc J 1979;40:870_6.

10. Brorson T, Skarping G, Renman L, Sangö C. Test atmospheres of diisocyanates with special reference to controlled exposure of humans. Int Arch Occup Environ Health 1989;61:495-501.

11. Lustgarten JA, Wenk RE. Simple rapid kinetic method for serum creatinine measurement. Clin Chem 1972;18:1419-22.

12. Miller JC, Miller JN. Statistics for analytical chemistry. Chichester (England): Ellis Horwood, 1984:96100.

13. Rowland M, Tozer TN. Clinical pharmacokinetics: concepts and applications. 2 nd ed. Philadelphia, PA: Lea \& Febiger, 1989.

14. Wass U, Belin L. An in vitro method for predicting sensitizing properties of inhaled chemicals. Scand J Work Environ Health 1990;16:208-14.

15. Palacian E, Gonzalez MP, Pineiro M, Hernandes F. Dicarboxylic acid anhydrides as dissociating agents of protein-containing structures. Mol Cell Biochem 1990; 97:101-11.

16. Eberson L, Landström L. Studies on cyclic anhydrides: IV. rate constants for the hydrolysis of some cyclic anhydrides exhibiting ring strain. Acta Chem Scand $1972 ; 26: 239-49$.

17. Pfäffli P, Savolainen H. Determination of 4-methylcis-hexahydrophthalic anhydride in human blood by gas chromatography with electron-capture detection. Analyst 1991;116:1333-6.

Received for publication: 26 August 1992 